\title{
OPTIMASI PERENCANAAN KEBUTUHAN LIFT PENUMPANG MENGGUNAKAN TRAFFIC VISION SYSTEM PADA BANGUNAN PERKANTORAN DI JAKARTA
}

\author{
Eilsa Adelia ${ }^{1}$, Johny Johan ${ }^{2}$ \\ ${ }^{1}$ Mahasiswa Magister Teknik Sipil, Universitas Tarumanagara, Jakarta \\ Surel: eilsadeliaa@gmail.com \\ ${ }^{2}$ Dosen Magister Teknik Sipil, Universitas Tarumanagara, Jakarta \\ Surel: johnyjohan@gmail.com
}

\begin{abstract}
The elevator, escalator and moving walk industries are an inseparable part of the construction industry. This industry has created the means of transportation that humans need to travel within a building. Planning a proper elevator planning must be done from the beginning of the planning of a building. This is done so that long queues do not occur in a building. One way that can be done is to coordinate with several experts in their fields such as elevator suppliers, to get the results of planning that is in accordance with SNI 03-6573-2001 standards. Optimization of elevator specification planning that is carried out using the Traffic Vision System has considered the factors that most influential towards the traffic in a building such as building area, vacancy factor, population or building occupant capacity, building function, elevator function and several other factors. Based on the results of the optimization carried out on 10 passenger elevator planning data in office buildings in Jakarta, this optimization affects the quantity, capacity, and speed of the elevator when implementing elevator planning. The average savings obtained is $5.01 \%$ of the contract value of a project and also has an average effect of $0.37 \%$ greater than the initial planning of the contract value of a project. This shows that the initial planning of the 10 passenger elevator data that was being investigated was included in the over specification category.
\end{abstract}

Keywords: Planning for elevator needs, Traffic Vision System, savings

\begin{abstract}
ABSTRAK
Industri lift, escalator dan moving walk merupakan bagian yang sulit dilepaskan dari industri konstruksi. Industri ini telah menciptakan alat transportasi yang dibutuhkan manusia untuk melakukan perjalanan di dalam suatu bangunan. Perencanaan kebutuhan lift yang baik perlu dilakukan sejak awal perencanaan suatu bangunan. Hal ini dilakukan agar tidak terjadi antrian yang panjang dalam suatu gedung. Salah satu cara yang dapat dilakukan adalah dengan melakukani koordinasi dengan beberapa pihak yang ahli dibidangnya seperti supplier lift, untuk mendapatkan hasil perencanaan yang sesuai standar SNI 03-6573-2001. Optimasi perencanaan spesifikasi lift yang dilakukan menggunakan Traffic Vision System telah mempertimbangkan faktor-faktor yang paling berpengaruh terhadap traffic pada suatu bangunan seperti luas bangunan, faktor kekosongan, populasi atau kapasitas penghuni gedung, fungsi gedung, fungsi lift dan beberapa faktor lainnya. Berdasarkan hasil optimasi yang dilakukan terhadap 10 data perencanaan lift penumpang pada bangunan perkantoran di Jakarta, optimasi ini berpengaruh terhadap kuantitas, kapasitas, dan kecepatan lift pada saat melaksanakan perencanaan lift. Penghematan rata-rata yang didapatkan sebesar 5,01\% terhadap nilai kontrak suatu proyek dan juga memiliki pengaruh rata-rata 0,37\% lebih besar dari perencanaan awal terhadap nilai kontrak suatu proyek. Hal ini menunjukkan bahwa perencanaan awal ke 10 data lift penumpang yang diselidiki termasuk kedalam kategori over specification.
\end{abstract}

Kata kunci: Perencanaan kebutuhan lift, Traffic Vision System, penghematan

\section{PENDAHULUAN}

\section{Latar Belakang}

Industri lift, escalator dan moving walk merupakan bagian yang sulit dilepaskan dari industri konstruksi. Industri ini telah menciptakan satu-satunya alat transportasi yang dibutuhkan untuk melakukan perjalanan di dalam gedung dengan cepat dan efisien. Selain dapat digunakan untuk mempersingkat waktu dan jarak tempuh, alat transportasi vertikal tersebut juga sangat membantu manusia dalam menjaga staminanya. Manusia tidak perlu lagi mengeluarkan tenaga lebih banyak untuk menaiki tangga dan akan berujung pada ketidakefisienan saat bekerja atau menjalankan aktifitas lainnya. Sebagai penunjang alat transportasi di dalam gedung, lift biasanya dilengkapi 
dengan kereta dan digerakkan dengan motor yang bergerak pada rel penuntun yang tetap terpasang di dalam ruang luncur yang juga dapat digunakan sesuai dengan permintaan pelanggannya. Adapun analisis pendekatan yang dilakukan menggunakan Traffic Vision System didasarkan kepada populasi pengguna yang akan dihubungkan dengan kecepatan, kapasitas, waktu tunggu, dan jumlah unit lift yang akan digunakan, agar nantinya didapatkan penjaminan terhadap kelayakan dan kenyamanan bagi seluruh pengguna gedung perkantoran tersebut. Traffic Vision tersebut merupakan suatu sistem yang diciptakan untuk memudahkan perencanaan lift yang sesuai dengan peraturan ISO terbaru.

\section{Rumusan masalah}

Adapun perumusan masalah dari penulisan ini adalah sebagai berikut:

1. Apakah ada pengaruh optimasi menggunakan Traffic Vision System terhadap kuantitas, kapasitas dan kecepatan lift yang akan digunakan?

2. Apakah ada pengaruh yang cukup signifikan dari optimasi perencanaan kebutuhan lift terhadap nilai kontrak suatu proyek?

\section{Tujuan penelitian}

Tujuan penelitian ini adalah untuk mengetahui spesifikasi kuantitas lift yang sesuai dengan kebutuhan dan dapat mengakomodasi keinginan customer dengan menggunakan Traffic Vision System dan juga untuk mengetahui perbandingan biaya antara jumlah dan spesifikasi lift berdasarkan data konsultan maupun sistem tersebut yang sesuai dengan peraturan SNI terhadap nilai kontrak suatu proyek.

Penelitian ini juga dimaksudkan sebagai dasar atau referensi bagi perencana maupun konsultan mekanikal dan elektrikal untuk merencanakan jumlah kebutuhan lift dan biaya yang dibutuhkan agar dapat mempersingkat waktu perencanaan. Selain itu, untuk menambah wawasan dan memastikan apakah perencanaan dengan menggunakan hitungan manual selama ini sudah tepat.

\section{METODE PENELITIAN}

Planning atau perencanaan adalah suatu rangkaian persiapan tindakan untuk mencapai tujuan. Perencanaan merupakan pedoman, garis-garis besar atau petunjuk-petunjuk yang harus dituruti, jika menginginkan hasil yang baik sebagaimana yang telah direncanakan. Metode perencanaan merupakan alur pemikiran yang ditempuh dalam menentukan perencanaan kebutuhan lift yang sesuai. Untuk menghindari pekerjaan yang berulang-ulang, maka dibuatlah diagram alir urutan pekerjaan. 


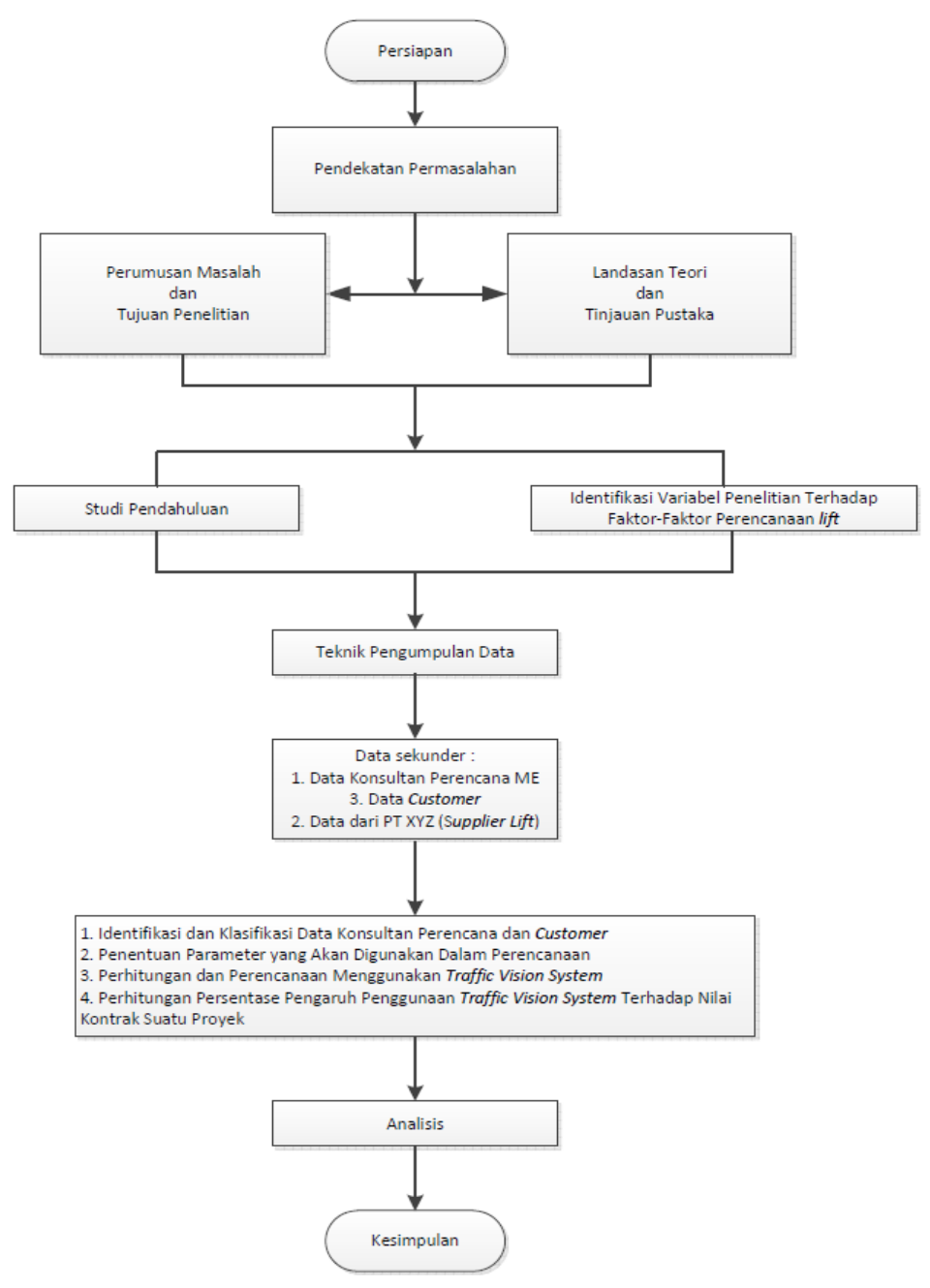

Gambar 1. Diagram Alir Penelitian

Adapun data-data yang akan digunakan pada penelitian kali ini adalah sebagai berikut:

1. Data primer merupakan data yang diperoleh langsung dari pengamatan di lapangan.

2. Data sekunder adalah data yang diperoleh secara tidak langsung atau dari catatan terdahulu.

Dalam penelitian ini data diperoleh dari konsultan perencana mekanikal elektrikal, customer dan PT XYZ yang merupakan salah satu supplier lift, escalator maupun moving walk terbesar didunia.

\section{HASIL DAN PEMBAHASAN}

Penelitian ini diawali dengan mengklasifikasikan data-data perencanaan awal yang disesuaikan dengan batasan masalah, yaitu jumlah pemberhentian antara 20-35 pemberhentian dan tinggi bangunan berkisar 75-170 meter. Oleh karena itu, didapatkan data-data sebagai berikut:

Tabel 1. Data Perencanaan Awal 10 Lift Penumpang Pada Bangunan Perkantoran di Jakarta

\begin{tabular}{cccccccc}
\multirow{2}{*}{ Office Segment } & Jumlah unit & $\begin{array}{c}\text { Kapasitas } \\
(\mathbf{K G})\end{array}$ & Kecepatan $(\mathbf{m} / \mathbf{s})$ & $\begin{array}{c}\text { Jumlah } \\
\text { stop }\end{array}$ & $\begin{array}{c}\text { Travel } \\
(\mathbf{m})\end{array}$ \\
\hline \multirow{2}{*}{ Office Tower 1 } & LZ & 5 & 1350 & 1,75 & $10 / 9 \mathrm{~F}$ & 36,20 \\
\cline { 2 - 7 } & HZ & 6 & 1350 & 3,00 & $20 / 13 \mathrm{~F}$ & 75,20
\end{tabular}




\begin{tabular}{|c|c|c|c|c|c|c|}
\hline \multirow{2}{*}{ Office Tower 2} & $\mathrm{LZ}$ & 5 & 1350 & 3,00 & $20 / 13 \mathrm{~F}$ & 74,80 \\
\hline & $\mathrm{HZ}$ & 5 & 1350 & 4,00 & $32 / 13 \mathrm{~F}$ & 125,80 \\
\hline \multirow{2}{*}{ Office Tower 3} & $\mathrm{LZ}$ & 4 & 1350 & 3,50 & $16 / 11 \mathrm{~F}$ & 60,40 \\
\hline & $\mathrm{HZ}$ & 4 & 1350 & 3,50 & $24 / 9 \mathrm{~F}$ & 94,80 \\
\hline \multirow{2}{*}{ Office Tower 4} & $\mathrm{LZ}$ & 3 & 1600 & 2,50 & $11 / 9 \mathrm{~F}$ & 45,80 \\
\hline & $\mathrm{HZ}$ & 3 & 1600 & 3,50 & $20 / 9 \mathrm{~F}$ & 84,60 \\
\hline \multirow{2}{*}{ Office Tower 5} & LZ & 4 & 1600 & 2,50 & $11 / 11 \mathrm{~F}$ & 49,20 \\
\hline & $\mathrm{HZ}$ & 4 & 1600 & 4,00 & $21 / 11 \mathrm{~F}$ & 91,20 \\
\hline \multirow{2}{*}{ Office Tower 6} & $\mathrm{LZ}$ & 7 & 1800 & 4,00 & $25 / 16 \mathrm{~F}$ & 118,80 \\
\hline & $\mathrm{HZ}$ & 6 & 1800 & 6,00 & $35 / 13 \mathrm{~F}$ & 170,40 \\
\hline \multirow{2}{*}{ Office Tower 7} & $\mathrm{LZ}$ & 4 & 1800 & 3,00 & $13 / 11 \mathrm{~F}$ & 52,80 \\
\hline & $\mathrm{HZ}$ & 4 & 1800 & 4,00 & $25 / 13 \mathrm{~F}$ & 102,00 \\
\hline \multirow{2}{*}{ Office Tower 8} & $\mathrm{LZ}$ & 6 & 1150 & 3,00 & $16 / 16 \mathrm{~F}$ & 63,80 \\
\hline & $\mathrm{HZ}$ & 6 & 1150 & 5,00 & $31 / 16 \mathrm{~F}$ & 126,80 \\
\hline \multirow{2}{*}{ Office Tower 9} & $\mathrm{LZ}$ & 4 & 1800 & 2,50 & $13 / 13 \mathrm{~F}$ & 53,70 \\
\hline & $\mathrm{HZ}$ & 4 & 1800 & 3,00 & $21 / 11 \mathrm{~F}$ & 89,50 \\
\hline \multirow{2}{*}{ Office Tower 10} & LZ & 6 & 1600 & 3,50 & $16 / 16 \mathrm{~F}$ & 72,40 \\
\hline & $\mathrm{HZ}$ & 6 & 1600 & 4,00 & $27 / 15 \mathrm{~F}$ & 125,15 \\
\hline
\end{tabular}

\section{Tahap analisis dan optimasi spesifikasi menggunakan Traffic Vision System}

Traffic Vision System merupakan sebuah analisis lalu lintas yang mempelajari kinerja sekelompok lift, berdasarkan asumsi tentang situasi lalu lintas yang diharapkan. Acuan utamanya adalah kapasitas penanganan dan waktu tunggu.

Hal yang pertama kali akan dilakukan adalah melakukan analisis pada data awal yang telah diberikan dengan menggunakan asumsi-asumsi yang didasarkan pada informasi yang diberikan oleh konsultan perencana maupun customer. Asumsi-asumsi tersebut meliputi populasi, luasan yang akan digunakan per-orang, luasan bersih dan luasan kotor yang akan ditempati, faktor kekosongannya, dan lain-lain.

Beberapa data dioptimasi dengan cara menurunkan salah satu diantara kapasitas maupun kecepatan. Akan tetapi, yang berpengaruh cukup signifikan adalah pengurangan jumlah unit lift yang akan digunakan. Pengurangan jumlah unit lift yang akan digunakan, akan memberikan banyak penghematan yang dapat dilakukan, seperti space yang awalnya digunakan sebagai shaft lift dapat digunakan atau disewakan untuk keperluan lainnya. Selain itu, penghematan yang sudah pasti dialami adalah berkurangnya beban biaya listrik dan perawatan. Hal ini sangat menguntungkan bagi pemilik bangunan. 
Optimasi yang dilakukan tetap harus mengacu pada batasan yang telah diberlakukan oleh SNI 03-6573-2001 seperti terlampir pada tabel di bawah ini:

Tabel 2. Tabel 5.2.2 SNI 03-6573-2001

\begin{tabular}{|c|c|c|c|l|}
\hline No. & Bangunan & $\begin{array}{c}\text { Waktu tunggu } \\
\text { rata-rata (WTR) } \\
\text { (dalam detik) } \\
\text { AWT }\end{array}$ & $\begin{array}{c}\text { Tuntutan Arus } \\
\text { Sirkulasi (TAS) } \\
\text { (dalam \% terhadap } \\
\text { jumlah penghuni tiap- } \\
\text { tiap 5 menit) }\end{array}$ & \multicolumn{1}{|l|}{$\begin{array}{l}\text { Pola sirkulasi jam } \\
\text { sibuk }\end{array}$} \\
\hline 1 & Gedung kantor mewah & $25 \sim 35$ & $10 \sim 12$ & Pagi hari, naik \\
\hline 2 & Gedung kantor komersial & $25 \sim 35$ & $11 \sim 13$ & Pagi hari, naik \\
\hline 3 & Gedung kantor instansi & $30 \sim 40$ & $14 \sim 17$ & Pagi hari, naik \\
\hline 4 & Hotel berbintang & $40 \sim 60$ & $8 \sim 10$ & Tengah hari imbang \\
\hline 5 & Hotel resort & $60 \sim 90$ & $6 \sim 8$ & Pagi hari, turun \\
\hline 6 & Rumah sakit & $40 \sim 60$ & 10 & Tengah hari imbang \\
\hline 7 & Apartemen & $60 \sim 90$ & $6 \sim 8$ & Pagi hari, turun \\
\hline 8 & Gedung kuliah & $40 \sim 90$ & 12.5 & Pagi hari, naik \\
\cline { 3 - 5 } & & & 25 & Tengah hari imbang \\
\hline
\end{tabular}

Tahap analisis dan optimasi biaya antara kebutuhan awal dan hasil optimasi terhadap nilai kontrak suatu proyek

Setelah dilakukan analisis dan optimasi spesifikasi, akan dilakukan analisis perbandingan antara perencanaan awal dan hasil optimasi terhadap nilai kontrak proyek dalam bentuk persentase.

Berdasarkan data perencanaan yang telah dilakukan dapat disimpulkan bahwa pada perencanaan awal, persentase rata-rata pengaruh perencanaan lift terhadap nilai kontrak suatu proyek adalah sebesar 5,38\%. Sedangkan, persentase pengaruh optimasi menggunakan Traffic Vision System adalah sebesar 5,01\%. Maka pada Grafik 1. di bawah ini dapat dilihat persentase selisih rata-rata hasil optimasi menggunakan Traffic Vision System terhadap perencanaan awal adalah sebesar $0.37 \%$.

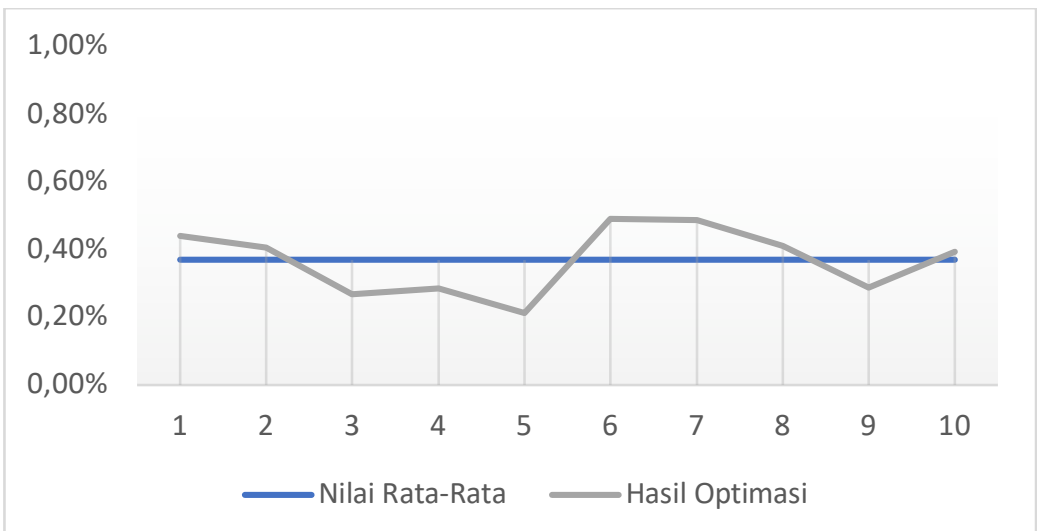

Gambar 2. Nilai selisih rata-rata hasil optimasi terhadap perencanaan awal

Tahap mengklasifikasikan spesifikasi dan biaya perencanaan lift berdasarkan luas total bangunan $\mathbf{m}^{2}$ 
Dari data perencanaan lift penumpang pada bangunan perkantoran di Jakarta yang diselidiki, dapat disimpulkan perencanaan spesifikasi dan perhitungan biaya perencanaan lift penumpang berdasarkan luas total bangunan $\mathrm{m}^{2}$. Adapun hasilnya adalah sebagai berikut:

Tabel 3. Spesifikasi dan Perkiraan Biaya Perencanaan Lift Pada 10 Proyek yang Diselidiki Berdasarkan Luas Total Bangunan $\mathrm{M}^{2}$

\begin{tabular}{|c|c|c|c|c|c|c|}
\hline $\begin{array}{c}\text { Luas Total } \\
\text { Bangunan } \\
\text { Perkantoran } \\
\text { (m2) }\end{array}$ & $\begin{array}{c}\text { Jumlah } \\
\text { Stops }\end{array}$ & $\begin{array}{c}\text { Travel } \\
\text { (m) }\end{array}$ & $\begin{array}{c}\text { Kecepatan } \\
(\mathrm{m} / \mathrm{s})\end{array}$ & $\begin{array}{l}\text { Kapasitas } \\
\text { (KG) }\end{array}$ & $\begin{array}{c}\text { Jumlah } \\
\text { Unit }\end{array}$ & $\begin{array}{l}\text { Harga per } \\
\text { Unit } \\
\text { (IDR Juta) }\end{array}$ \\
\hline \multirow{2}{*}{18,192} & \multirow{2}{*}{20} & 45,80 & 1,50 & 1150 & 3 & 1.100 \\
\hline & & 84,60 & 3,00 & 1350 & 3 & 1.450 \\
\hline \multirow{2}{*}{21,100} & \multirow{2}{*}{21} & 53,70 & 2,00 & 1600 & 4 & 1.250 \\
\hline & & 89,50 & 3,00 & 1600 & 4 & 1.550 \\
\hline \multirow{2}{*}{22,500} & \multirow{2}{*}{24} & 60,40 & 2,00 & 1275 & 4 & 1.300 \\
\hline & & 94,80 & 2,50 & 1275 & 4 & 1.500 \\
\hline \multirow{2}{*}{24,859} & \multirow{2}{*}{32} & 74,80 & 2,00 & 1275 & 5 & 1.500 \\
\hline & & 125,80 & 3,50 & 1350 & 5 & 1.950 \\
\hline
\end{tabular}

Tabel 4. Spesifikasi dan Perkiraan Biaya Perencanaan Lift Pada 10 Proyek yang Diselidiki Berdasarkan Luas Total Bangunan $\mathrm{M}^{2}$ (lanjutan)

\begin{tabular}{ccccccc}
$\begin{array}{c}\text { Luas Total } \\
\text { Bangunan } \\
\begin{array}{c}\text { Perkantoran } \\
(\mathbf{m} 2)\end{array}\end{array}$ & $\begin{array}{c}\text { Jumlah } \\
\text { Stops }\end{array}$ & $\begin{array}{c}\text { Travel } \\
(\mathbf{m})\end{array}$ & $\begin{array}{c}\text { Kecepatan } \\
(\mathbf{m} / \mathbf{s})\end{array}$ & $\begin{array}{c}\text { Kapasitas } \\
(\text { KG })\end{array}$ & $\begin{array}{c}\text { Jumlah } \\
\text { Unit }\end{array}$ & $\begin{array}{c}\text { Harga } \\
\text { per Unit } \\
\text { (IDR } \\
\text { Juta) }\end{array}$ \\
\hline \multirow{2}{*}{29,200} & 21 & 49,20 & 2,00 & 1350 & 4 & 1.250 \\
\cline { 3 - 7 } & 25 & 51,20 & 4,00 & 1350 & 4 & 1.750 \\
\cline { 3 - 7 } 29,691 & 102,00 & 4,00 & 1800 & 4 & 2.650 \\
\hline \multirow{2}{*}{30,745} & 27 & 72,40 & 2,00 & 1600 & 5 & 1.350 \\
\cline { 3 - 7 } & & 125,15 & 3,50 & 1350 & 6 & 1.850 \\
\hline
\end{tabular}




\begin{tabular}{lcccccc}
\hline \multirow{2}{*}{31,987} & 31 & 63,80 & 2,50 & 1350 & 5 & 1.350 \\
\cline { 3 - 7 } & & 126,80 & 4,00 & 1350 & 6 & 2.050 \\
\hline \multirow{2}{*}{37,716} & 20 & 32,30 & 1,75 & 1350 & 3 & 1.100 \\
\cline { 3 - 7 } & & 75,20 & 2,50 & 1350 & 6 & 1.450 \\
\hline \multirow{2}{*}{44,265} & 35 & 118,80 & 4,00 & 1800 & 6 & 2.750 \\
\cline { 3 - 7 } & & 170,40 & 5,00 & 1600 & 6 & 2.700 \\
\hline
\end{tabular}

\section{KESIMPULAN DAN SARAN}

\section{Kesimpulan}

Berdasarkan hasil analisis yang telah dilakukan terhadap 10 data perencanaan lift penumpang pada perkantoran di Jakarta dengan jumlah pemberhentian antara 20-35 pemberhentian dan dengan tinggi bangunan berkisar 75-170 meter, dapat ditarik kesimpulan sebagai berikut:

1. Traffic Vision System berpengaruh terhadap kuantitas, kapasitas dan kecepatan pada perencanaan lift apabila dilihat dari hasil analisis 10 data lift penumpang pada bangunan perkantoran di Jakarta.

2. Didapatkan penghematan yang cukup signifikan dari perencanaan awal apabila dilihat dari hasil optimasi 10 data lift penumpang pada bangunan perkantoran di Jakarta. Hal ini menunjukan bahwa perencanaan awal ke 10 lift penumpang tersebut mengalami over specification.

3. Pengaruh hasil optimasi dari 10 data perencanaan kebutuhan lift penumpang pada bangunan perkantoran di Jakarta terhadap nilai kontrak suatu proyek dirata-ratakan sebesar 5,01\%. Sedangkan, selisih rata-rata terhadap perencanaan awal sebesar $0,37 \%$.

\section{Saran}

Saran yang dapat diberikan adalah sebagai berikut:

1. Beberapa hal yang harus diketahui sebelum merencanakan spesifikasi lift pada suatu bangunan, yaitu luas bangunan, populasi atau kapasitas penghuni gedung, fungsi gedung (perkantoran, gedung sekolah, rumah sakit, apartemen dan lainnya), fungsi lift, serta waktu dan jumlah beban puncak.

2. Perlu adanya koordinasi yang baik sebelum menentukan perencanaan lift untuk menghindari antrian yang panjang pada suatu gedung, yaitu dengan cara memperhitungkan faktor-faktor kritis secara benar.

3. Koordinasi dengan supplier lift juga merupakan awal yang baik dalam merencanakan kebutuhan lift pada suatu gedung, karena supplier lift memiliki pengalaman dan pertimbangan tertentu dalam perhitungan traffic lift pada suatu bangunan, dan dengan melakukan optimasi perencanaan menggunakan software yang dimiliki setiap supplier lift dengan tepat dapat menghindari kelebihan biaya pada perencanaan pengadaan lift dan juga menghindari antrian panjang jika kekurangan pada perencanaannya.

\section{REFERENSI}

Company Profile BCI Asia (Indonesia).

Company Profile PT. XYZ Lifts.

Journal: Andri Sulistyo. 2016. Optimasi Perhitungan Ulang Kebutuhan Lift Penumpang Type IRIS-NV PA 20 (1350) CO105 Pada Gedung Apartemen 17 Lantai. 
Journal: Indra Jaya Barus. 2008. Perencanaan Lift Untuk Keperluan Gedung Perkantoran Berlantai Sepuluh.

Journal: Michael Godwin. 1987. Intensive Traffic Passenger Lifts, Facilities, Vol. 5 Iss 1 pp. 11 15.

SNI 03-6573-2001: Tata Cara Perancangan Sistem Transpotasi dalam Gedung (lift). 